\title{
Tradiciones orales en torno a los duendes y otros seres sobrenaturales asociados al agua en el pueblo de Tepec, en la región sur de Jalisco (México)
}

\section{Oral traditions related to goblins and other supernatural entities associated with water in Tepec, in the southern region of Jalisco (Mexico)}

\author{
Víctor Manuel BañUelos Aquino \\ (Universidad de Guadalajara) \\ banuelosaquino@gmail.com \\ ORCID ID: 0000-0002-0630-0536
}

\begin{abstract}
In the southern region of the state of Jalisco is the town of Tepec, one in which there are various traditions around goblins and other supernatural entities associated with water. After considering two stories of narrators of the place, we realize the type of representations that in this town are made of these imaginary beings: as entities that steal from children and that are linked to water. So, in this analytical exercise, the way in which these supernatural beings are represented in this region will be shown, considering other figurations that have been made of similar entities in other parts of the country, to find points of similarity and difference that they show us the most particular characteristics of these imaginary characters in this locality.
\end{abstract}

KeYwords: Jalisco folklore, legends, goblins, fairy entities, water spirits
RESUMEN: En la región sur del estado de Jalisco está el pueblo de Tepec, uno en el que existen diversas tradiciones en torno a los duendes y otras entidades sobrenaturales asociadas con el agua. Tras tomar en cuenta algunos relatos de narradoras del lugar, nos percatamos del tipo de representaciones que en este poblado se hacen de estos seres del imaginario: como entidades que se roban a los niños y que son vinculadas con el agua. De manera que en este ejercicio analítico se mostrará la manera en que se representa a estos seres sobrenaturales en esta región, tomando en cuenta otras figuraciones que se han hecho de entidades similares en otras partes del país, con la finalidad de encontrar puntos de similitud y diferencia que nos muestren las características más particulares de estos personajes del imaginario en esta localidad.

Palabras-clave: Folclor de Jalisco, leyendas, duendes, entidades feéricas, espíritus del agua

Se hallaba visiblemente perseguida y molestada de un demonio de los que el vulgo llama duendes. Le hacía mil burlas pesadas de las que la pobre mujer quedaba atemorizada, maltratada y corrida (Artemio de Valle-Arizpe, Historia, tradiciones y leyendas de las calles de México) 
INTRODUCCIÓN: A PROPÓSITO DE UNA REGIÓN FOLCLÓRICA DE JALISCO

Este ejercicio reflexivo es parte de una serie de investigaciones de campo que he realizado en la zona sur del estado de Jalisco, en México (ver mapa en la figura 1), que por sus particularidades puede conformar una suerte de región con una identidad folclórica propia. Ya con anterioridad he tenido la oportunidad de introducir la región folclórica del sur de Jalisco (Bañuelos Aquino, 2020: 63-74) en la que, tomando en cuenta las características de estas comunidades y su tipo de imaginario, que hace que diversas localidades compartan un mismo corpus de leyendas y tradiciones religiosas, se pudo concluir que tenían propiedades que las distinguían de otras regiones folclóricas del estado.

Las actividades económicas más representativas de esta parte del estado, cuanto más en el pueblo de Tepec, se derivan de la venta de artículos como la nuez, el fruto de la pitaya y el café, que desde hace décadas suelen venderse en las fiestas religiosas de las poblaciones aledañas. Las condiciones mercantiles de estos municipios nos pueden ayudar a homologar esta zona en una región delimitada, sin embargo, no será a partir de sus modelos económicos que demarcaremos el área que queremos analizar, puesto que nuestro interés recae en los imaginarios religiosos de una parte de su población, razón por la que haremos una delimitación espacial desde la perspectiva de los estudios de la narrativa de tradición oral y la teoría de las regiones folclóricas.

Cuando una o más comunidades crean una suerte de identidad propia, a partir de sus tradiciones culturales, estas conforman una suerte de región folclórica, es decir, una en la que las personas que la constituyen comparten creencias y formas culturales gracias a que tienen un pasado y unas condiciones de vida comunes (Zavala Gómez del Campo, 2013: 29-36). Estos elementos comunales que crean una identidad son los que le dan sentido a los temas y motivos que se manifiestan en la literatura regional, en los que las raíces tradicionales dotan de una carga de significado a estas leyendas y tradiciones populares (Martínez Morales, 2006: 11-12). Estos razonamientos teóricos aplicados a nuestro objeto de estudio nos permiten ver diversas tradiciones compartidas en torno al agua y las entidades que se pensaba estaban vinculadas con ella, y que tienen un significado determinado por los pobladores de esta región.

Por lo tanto, para sustentar la existencia de esta región folclórica, entendemos que estos elementos comunes que ayudan a crear una identidad local también dan forma a los temas y motivos que se manifiestan en la literatura regional y son reconocidos por la población local. En nuestro caso particular, veremos que la aparición de tradiciones orales sobre los espíritus del agua está vinculada con espacios muy bien identificados por la



Figura 1: Mapa con ubicación de la región sur de Jalisco. En color verde se muestran los municipios que conforman esta región en particular. Fuente INEGI/ CONABIO (2010) 
población tepecana, por lo que son relatos con una carga semántica bien definida y precisa para la gente de esta comunidad.

En este estudio trabajaremos tradiciones en torno a los espíritus del agua en un pueblo en particular llamado Tepec, que pertenece al municipio de Amacueca (ver mapa de la figura 2), ubicado a cinco kilómetros de la cabecera municipal, que ha sido reconocido en la literatura por las enormes huertas y nogaleras que tuvo antaño, razón por la que aparece en crónicas de la región (Sandoval Godoy, 1985: 20-28). También ha sido alabado por la tradición de sus músicos, de bandas que amenizaban fiestas y eventos de importancia, principalmente durante la primera mitad del siglo XX; aparecen por ello incluso en el cuento de Juan Rulfo, «El día del derrumbe» (Rulfo, 2005: 135-143). Es un pueblo antiguo, de religión católica, por lo que al año se desarrollan diversas festividades en las que se conjuntan las fiestas patronales con ferias destinadas a vender los productos más icónicos de la región.

Tras considerar todo lo anterior, haremos un acercamiento a la manera en que en esta población se representa a las entidades sobrenaturales del agua: por un lado, los duendes y por otro la Llorona, seres vinculados con arroyos y ríos en esta tradición que mantienen diferentes funciones puesto que los primeros suelen robarse a los niños y la segunda aparece para augurar desgracias. Veremos que la asociación entre estos dos personajes con el elemento líquido es la cuestión que los relaciona en esta región, en cuanto a que ambos son espíritus del agua. A la par, también se apreciará como sus representaciones son a la vez semejantes a otras que existen en otras narrativas populares mexicanas. La finalidad de este análisis será doble: por un lado, se buscará exponer estos relatos de modo general, para presentar esta tradición fuera de esta región folclórica; y por el otro, mostrar las similitudes y diferencias de estos seres con otros del país, para ver al final las particularidades que tienen estos personajes del imaginario de esta región.

\section{LOS DUENDES Y LOS NIÑOS}

Sobre los duendes en la tradición popular de México se ha escrito mucho, desde los que aparecían en las tradiciones de Mesoamérica hasta los que llegaron a ser documentados en los expedientes instruidos por el Santo Oficio de la Inquisición en la Nueva España, ya dotados en estos registros de un sentido cristiano y por lo tanto vinculados con demonios de baja calaña (Ayala Calderón, 2010: 264-268). Se ha especulado que la palabra duende

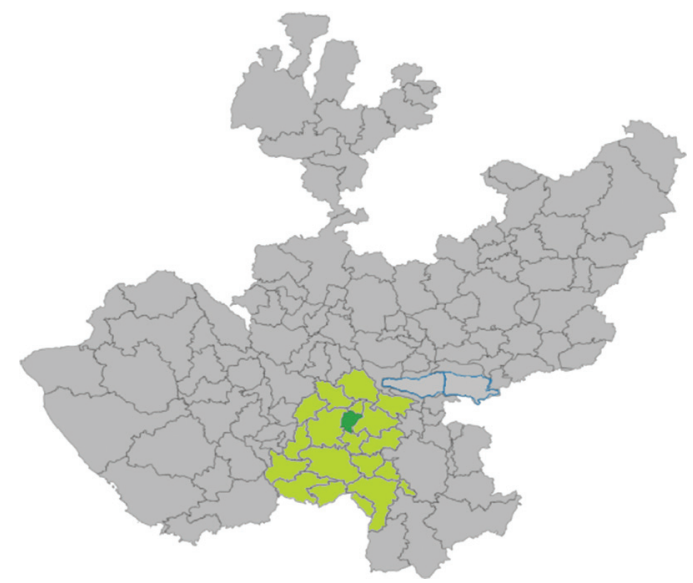

Figura 2: Mapa con la ubicación específica del pueblo de Tepec, en verde oscuro, en la región Sur de Jalisco. Fuente INEGI/ CONABIO (2010) 
proviene de la raíz indogermánica: dema, que se usaba para designar cosas vinculadas con la casa y el hogar, estando ligada lingüísticamente con el término latino: domus, casa, por lo que constantemente se va a ver a este ser molestando a las personas en sus hogares (Ayala Calderón, 2017: 179).

En el seno del cristianismo medieval se creó una tradición que buscaba explicar funcionalmente la existencia de diversas entidades sobrenaturales que habitaban en regiones agrestes, entre ellas los duendes y las hadas, y que decía que estas eran los ángeles que habían decidido no tomar partido en la lucha contra Satanás, por lo que Dios los arrojó del Cielo pero no los envío al Infierno, relato que esclarecía el porqué de la naturaleza de estos seres que en muchas ocasiones parecía contraria a Dios o cuando menos molesta hacia los cristianos (Ayala Calderón, 2010: 264-266).

En suma, los duendes son entidades sobrenaturales que existen en el imaginario de diversas regiones de México y del mundo, y que tienen algunas características bien definidas como: tener una baja estatura, ser habitantes de los bosques, los ríos y las cuevas, estar ligados con elementos como la tierra y el agua, y que constantemente se meten en las casas y asentamientos de los seres humanos para molestarlos o ayudarlos (Ayala Calderón, 2010: 260-263).

Algunos de los más populares son los chaneques, personajes del folclor mesoamericano, del sur de México, que suelen ser descritos como entidades pequeñas que habitan bajo tierra y que por lo general están desnudos. Estos seres sobrenaturales a menudo recibían ofrendas de la población con la finalidad de que los protegieran a ellos y a sus cosechas, de la tierra y el agua, función que se les atribuye a estos personajes que ha hecho pensar que pueden ser derivados o residuos de dioses nativos precristianos (Pérez Castro, 2015: 74-75). Aunque algunos autores han insistido en que duendes y chaneques no son lo mismo, tanto su función en la tradición popular como su forma y aspecto son iguales (Ortiz Guillén, 2016: 81).

A la par, existen también numerosos relatos sobre este tipo de entidades sobrenaturales en el centro del país. Por ejemplo, Artemio de Valle-Arizpe, en sus compilados de leyendas y tradiciones mexicanas de la época de la Colonia, nos presenta en su leyenda, Un duende y un perro, el caso de un duende que era aparentemente invisible a los ojos de la gente, aunque lo podía ver y sentir una mujer de nombre doña Luisa de Cervantes, la cual era constantemente víctima de las bromas y los golpes de esta entidad que en este contexto era asociada con el demonio. Así lo cuenta de Valle Arizpe en su leyenda:

Doña Luisa de Cervantes, casada con Alonso de Valdés, regidor de esta ciudad, se hallaba visiblemente perseguida y molestada de un demonio de los que el vulgo llama duendes. Le hacía mil burlas pesadas de las que la pobre mujer quedaba atemorizada, maltratada y corrida. Le daba golpes y bofetadas tremendas en el rostro, dejándoselo señalado y moreteado de los continuos porrazos. Si estaba en vistas con otras damas, de pronto se le salían los guantes de las manos, o bien en presencia de todas, de repente, se le escapaban los chapines sin saber cómo y se iban saltando por el estrado, llevándolos el invisible duende de una parte a otra, y muchas veces, en lo más animado de la conversación, le veían la cara manchada de carbón o de tinta, que el demonio le ponía para enfrentarla, y, lo que era peor, en varias ocasiones le desató y le bajó rápidamente las enaguas, y esto ante señores, con lo que no le quedaba a doña Luisa más remedio que dar un grito y desmayarse.

Cuando iba en su carroza, el maldecido duende le descalzaba las jervillas y arrojábalas por el aire a vista de cuantos pasaban por la calle, y si en su casa estaba ocupada en 
su labor y almohadilla, arrebatándosela de las manos se la echaba por las ventanas, y, finalmente, a todas horas y en todos lugares, y aun en las mismas iglesias, no dejaba de perseguirla, quitándole el manto, desgarrándoselo y rompiéndole el libro de sus oraciones o sus novenas, tirándole el rosario, y muchas veces se le presentó en varias formas y figuras horrendas. La atemorizaba de día y de noche de tal manera, que vivía muriendo doña Luisa. (Valle-Arizpe, 2008: 44)

Esta naturaleza violenta y diabólica de los duendes es común en relatos documentados en folios inquisitoriales de la Nueva España, puesto que, como parte del discurso evangelizador, los monjes habían vinculado a antiguas deidades y espíritus de los campos precolombinos con el diablo, sus avatares, y secuaces (Ayala Calderón, 2010: 263-268), por lo que es común encontrar relatos de duendes en los documentos de las distintas inquisiciones que se instalaron en Hispanoamérica (Carranza, 2019: 263). Este proceso de asimilación se observa en las narraciones documentadas por el Santo Oficio, como lo evidencia un testimonio en el que supuestamente un duende respondía a las preguntas que le hacía su conjurador, golpeando una caja de acuerdo lo ameritara la respuesta que tuviera que dar, según se relata en la acusación que hiciera ante el Tribunal del Santo Oficio, Francisca de Castañeda en 1650 (Ayala Calderón, 2010: 268-269).

También existen relatos en los que los duendes se llevan a las muchachas y muchachos para tener contacto carnal (Carraza, 2019: 270). Un caso particular sobre este tema lo comparte el historiador Javier Ayala Calderón, mismo que recogió de los acervos de la Inquisición novohispana, narrado por un muchacho de 26 a 28 años, quien en 1676 le narró lo siguiente a los oficiales del Santo Oficio:

de la persecución que sufría por parte de un duende [...] que durante un tiempo la relación entre ellos había sido tan extremadamente «cordial», que muchas veces el duende se le acostaba en los brazos, dormía con él y, de hecho, hasta habían tenido comercio carnal en el monte, obteniendo con él el mismo deleite que se tenía con una mujer. A pesar de su excitante inventiva, una historia como esta pronto motivó el desconcierto y un profundo desagrado de su auditorio cuando el joven aclaró que la figura del duende solía ser la de un «frailecito pequeño de San Francisco», si bien - insistió - cuando habían sostenido relaciones sexuales siempre había sido con forma de mujer (Ayala Calderón 2010: 273-274).

Ciertamente, los motivos con los cuales solía representarse a los duendes en los folios inquisitoriales eran muy similares a los que se les atribuían en la tradición oral hispánica, en la cual eran conocidos por hacer travesuras y producir ruidos extraños dentro de las casas (Carranza, 2019: 270). A la luz de lo anterior, podemos notar que los duendes en la tradición de la Nueva España y posteriormente de México suelen tener una naturaleza tanto protectora, como en el caso del chaneque, como también hostil o molesta hacia los seres humanos.

De modo más cercano a las narraciones que vamos a abordar de la región folclórica del sur de Jalisco, tanto en espacio como en temporalidad, tenemos el relato de un diablillo que se cuenta cerca de Guadalajara, la capital del estado de Jalisco; allí se dice que aparece una suerte de duende arborícola. Este diablillo se hacía llamar Abigar, probablemente una deformación del nombre Abigor atribuido a un demonio del cristianismo, y fue atrapado según el relato en Guadalajara en el año de 1906 por siete monjes que lo aprisionaron en un baúl, tras hacerlo salir de un árbol cercano a una casa, el cual supuestamente sigue en el 
jardín de esa propiedad hasta nuestros días, según nos relata Marino Quezada Hernández en su compilado de narraciones populares tapatías:

Un día, a eso de las 6 de la tarde, los niños jugaban alrededor del árbol; era una bola de gusto y Abigar se mortificaba con ese relajo de tanto niño ya que era la hora de su siesta y, como estaba de mal humor, decidió que, para ahuyentarlos, se dejaría ver por uno de ellos y con gestos le mostraría su enojo, el niño lo vio y dejó de jugar. «Ay qué bueno, haré lo mismo con los demás para que me dejen vivir tranquilo». Al día siguiente Pedrito dijo que había un monillo que le hacía gestos, los demás niños no le creyeron pero luego ellos también lo vieron. Uno de ellos le contó a su mamá y la llevaron para que viera que era cierto, la mujer platicó con la dueña de la casa y juntas se acercaron a donde jugaban los niños, ellas también lo vieron y ese día Abigar comenzó a insultarlos a todos, ofendiéndolos con toda clase de groserías y ofensas que se sabía. (Quezada Hernández: 2008: 33-34)

En este relato se advierte la representación de los duendes como entidades hostiles al ser humano común en la narrativa oral de este estado, pues, aunque Abigar se estaba mostrando amenazador por causa de la invasión de su propiedad, fue asociado al mal por los niños y los monjes que de modo posterior lo encerraron en el baúl. A la par se aprecian temas y motivos recurrentes del duende: el acercamiento de este con los niños, las fricciones que pueden suscitarse tras su convivencia con los seres humanos y en este caso, de manera similar a los folios de la Inquisición, su conflicto con los representantes de la Iglesia, al llamarse sospechosamente parecido a un demonio de la tradición cristiana y ser derrotado por siete monjes.

En la tradición oral de la región sur de Jalisco, más específicamente del pueblo de Tepec, el duende no aparece ciertamente vinculado ni con los demonios ni con los espíritus protectores del campo, veremos que en las creencias de este poblado se piensa que estos seres buscan robarse a los niños, un aspecto aterrador pero no asociado con el Diablo, para llevárselos lejos de sus padres, valiéndose de diversos recursos como sus poderes preternaturales, que les dan fuerza descomunal y la posibilidad de atravesar las paredes, así como también su apariencia bonachona, aspectos que se pueden ver en el siguiente relato:

Cuando estábamos en Tepec, la recamara donde estaba dormida Nena, la puerta para entrar era de madera antigua, pero, cosa extraña, le empujaba yo queriendo entrar y no, no se podía. Estaba como que la hubieran atrancado y, este, ya, en un momento, izas, se abrió! Y entonces me dijo tu mamá, ya no se acuerda, tu mamá me dijo: «Es que los duendes estaban todos ahí; este, tú empujabas y ellos empujaban también para que no pudieras abrir». Fíjate, los duendecillos, le dice, y ya después dice: «No podías abrir, pero se cansaron ellos de estar empujando y se metieron a la pared». Estaba la Nena, tu mamá, chiquita, de unos seis o siete años, y yo le pregunto ahora: «¿Nena cómo eran los duendes?». «Ah, pues no me acuerdo».

Y también, Beto y Tabo, que estaban chiquitos, tendrían unos seis años, seis o siete, y como la casa tiene huerta, les gustaba mucho irse allá a la huerta y decían: «Vámonos a jugar con los chiquitos». Y yo les preguntaba: «¿Cómo son los chiquitos?», y no me contestaban, no me decían. Serían duendes, me imagino. Iban a jugar con ellos.

Más antes, cuando yo era niña, entonces no había agua corriente en la casa, no había, en las casas no había agua, había que acarrearla. Entonces, para lavar la ropa, como dicen, para hacer la colada, o sea, lavar la ropa, iban al río, iban a un río, era un arroyo y ahí lavaban, pero... Me acuerdo yo que a mi mamá le decía una vecina: «Háblele a Silvia 
porque, si no, los duendes se quedan con su espíritu», y entonces: «Silvia, no te quedes; Silvia, no te quedes», Ja, ja, ja. ${ }^{1}$

En este relato aparecen varios motivos folclórico-narrativos que se hallan catalogados en el canónico Motif-Index de Thompson (1955-1958); en concreto el de Fairy steals child from cradle, los Niños robados por las hadas (F321) y Fairies carry people away to Fairyland, los Cautivos en el país de las hadas (F320; F301.3), puesto que, aunque los seres sobrenaturales no lograron llevar a buen término su cometido de robar a los niños, esta era su intención primaria. Lo anterior nos muestra las creencias alusivas a esta espeluznante actividad que se atribuía a los duendes y que los vinculan con otros pertenecientes a otras tradiciones similares en diversos países, debido a que en variadas tradiciones orales se decía que estas entidades practicaban el robo de infantes.

De hecho, en la parte final de la entrevista, la narradora nos menciona que se pensaba que los duendes se «quedan con su espíritu», es decir, se sabía en el folclor popular que estos se robaban el alma de los niños aprovechándose de su aspecto dulzón, puesto que se les representa como seres pequeños, «los chiquitos», que se iban a jugar con los niños, quienes aparentemente tenían la cualidad de verlos o bien gozaban del permiso de los duendes para esto.

La canción, que es la misma que puede escucharse en alguno de los registros accesibles en el Corpus de Literatura Oral, Silvia, no te quedes; Silvia, no te quedes ${ }^{2}$, es un documento valioso del folclor en torno a este tipo de tradiciones en Tepec y nos ilustra del miedo que provocaba dejar a los niños cerca de los espacios acuáticos, posiblemente por los riesgos que existen al dejarlos jugando junto a los ríos o a los lagos sin la supervisión de un adulto. En el ejemplo, la narradora nos dice que su madre le cantaba: «Silvia, no te quedes; Silvia, no te quedes», sin embargo, se puede concluir que esta tonada del dominio comunal podía modificarse según lo ameritara la situación, cambiando el nombre del niño al que se le recitara, lo cual nos muestra una tradición compartida por esta comunidad que temía que los niños pudieran ser cambiados, robados o perdidos por el actuar de estos duendes.

Como se mencionó líneas atrás, el motivo del robo de los niños por parte de las hadas u otras entidades sobrenaturales es común y reconocible en diversas culturas; como ejemplo está el caso español del relato, La fuente de la Julianita (María Merino, 2010: 135-137), en donde se cuenta cómo el duende de una fuente, enamorado de una niña, la convence de irse con él dentro del agua de donde jamás volvió a salir la Julianita. Probablemente algunos elementos particulares de estas tradiciones en España hayan sido introducidos en la Nueva España durante la Conquista y el período colonial y, como ocurrió con el caso de otros personajes del imaginario, como el diablo y los santos, tras su apropiación se convirtieron en motivos recurrentes de esta tradición en distintas regiones de México (Bierhorst, 2003: XV-XIX).

\footnotetext{
${ }^{1}$ La narradora fue Silvia López Bañuelos, maestra de primaria, originaria de Tepec, Amacueca, residente de Guadalajara, 84 años. Recogió: Víctor Manuel Bañuelos Aquino. Versión en línea de la grabación y la transcripción en la página web: https://corpusdeliteraturaoral.ujaen.es/archivo/0873n-los-duendes-entepec-amacueca.

${ }^{2}$ La narradora fue Silvia López Bañuelos, maestra de primaria, originaria de Tepec, Amacueca, residente de Guadalajara, 84 años. Recogió: Víctor Manuel Bañuelos Aquino. Versión en línea de la grabación y la transcripción en la página web: https://corpusdeliteraturaoral.ujaen.es/archivo/0873n-los-duendes-entepec-amacueca.
} 
Lo cierto es que relatos sobre niños y duendes cerca del agua se siguen contando en diversas regiones de México hasta el día de hoy como se revela en la siguiente narración de un oriundo de Xochimilco, Ciudad de México, recogido en el año 2007:

En ese pueblo había de todo: lloronas; autiotas, que eran mujeres que les pegaban a las otras mujeres que veían embarazadas, porque las autiotas no se podían embarazar, porque habían abortado, y ese era su castigo; duendes, con esos nos poníamos a jugar yo y mis hermanos. Eran unos niñitos chiquitos y siempre andaban encuerados, andaban por donde íbamos a sacar agua dulce, y cuando nos acercábamos nos aventaban piedras, y nosotros se las regresábamos y así jugábamos. Silvestre Moreno Romero, chofer, mayo, 2007. (Campos Moreno, 2008: 72)

Otro ejemplo nos revela que también se tiene esta concepción del duende en la región sur del país, en donde se les considera parecidos a los niños y afines a jugar con los infantes:

Una niña, pero en Xico, viene siendo mi sobrina pero ya lejana. Dicen que esa niña fue a la leña con su mamá. Fue con otra amiga y se fueron a traer leña, a picar leña para la lumbre. Y dicen que escuchaban la niña que se oía lejos. Eran dos hermanitas, pero la más grandecita sí andaba con su mamá ahí en la finca y la otra niña, dicen que ya estaba subida en el puente. Pero haz de cuenta que en el puente, en la bardita que tiene, ahí estaba. Porque dice que la llamaban unos niños, chiquititos, y que le daban juguetes. «Es que me llaman», dice. «Bueno, niña, ¿qué estás haciendo?», la regañó su mamá, y dice: «Es que quiero alcanzar los niños que me están llamando, que me van a dar unos juguetes bien bonitos, tienen unas muñequitas pero bien bonitas, bonitas». Y ya, la llamaban, y dice que no se quería regresar. Y ya, tuvo que correr la mamá a agarrarla porque ya ves que está bien hondo ese río, está bien hondo. (Ortiz Guillén, 2016: 84)

En esta clase de relatos veracruzanos se hace hincapié en la peligrosidad de estos seres, puesto que pueden perder a los niños, aunque también a los cortadores de leña, manipulando mágicamente las fincas e incluso atacar a los que pretenden seguirlos (Ortiz Guillén, 2017: 97-99).

En suma, podemos encontrar en estas pequeñas narraciones, tres características de los duendes de Tepec: son parecidos a los niños, buscan llevarse a los infantes, y se les ve como espíritus del agua. Esta idea de que los duendes habitaban en ríos y arroyos nos lleva a otro apartado de este ensayo, en el que veremos la cuestión de los cuerpos de agua como habitáculos de estos y otros espíritus acuáticos; todo esto a la luz de otro ejemplo de esta tradición en Tepec, en el que además se ve la vinculación que se hace en esta región de los duendes con la Llorona, por compartir estos el elemento acuático.

\section{LOS ESPÍRITUS DEL AGUA EN EL ÁRBOL DEL TECOLOTE}

El agua es una parte importante del paisaje, de la identidad, del carisma de esta región, famosa por su agua y las huertas que esta riega (Sandoval Godoy, 1985: 20-28); el agua pone el fondo de diversas tradiciones y narraciones, como la ya mencionada de los duendes, y otras que incluso han quedado registradas en epigrafía diversa, desde la dejada por los pueblos originarios de la región, antes de la llegada de los españoles, hasta la que conmemora las luchas que hubo entre pueblos diversos por este valioso recurso. 


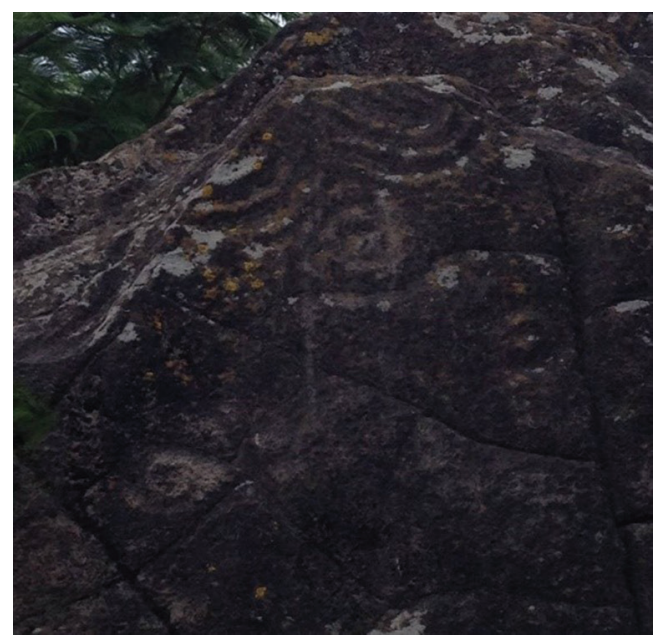

Figura 3: Piedra con glifos alusivos al agua en la entrada de Tepec, la gente de la población especula que esta roca indicaba la cercanía de aguas subterráneas en la zona. Foto tomada el 26 de junio de 2015.

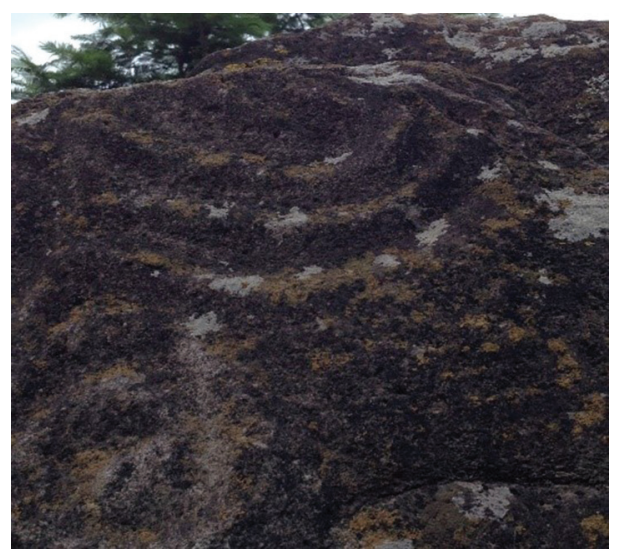

Figura 4: Piedra con glifos alusivos al agua (detalle). Foto tomada el 26 de junio de 2015.

Este líquido ha tenido tremenda presencia en el imaginario tepecano desde antes de la evangelización de la zona. Hay rocas de gran tamaño, como una que se encuentra a la entrada del pueblo (ver figura 3), en que se pueden ver diversos glifos, marcados con alguna herramienta punzocortante, con formas ondulantes y circulares (véase figura 4), que se especula servían para marcar zonas donde había nacimientos de agua.

La epigrafía en piedras de gran tamaño no se limita, en esta población, a estos ejemplos; hay también una roca de gran tamaño que alude al asesinato de una oriunda de la región en una pugna por el agua en el año de 1915; esto ocurrió tras constantes peleas y confrontaciones que habían tenido dos mujeres del pueblo debido a que ambas reclamaban el derecho de extracción del agua de un pozo local. La inscripción de la roca dice: «El día 26 de febrero de 1915 fue asesinada Abelarda por el agua» (véase figura 5).

No faltan los relatos en los que los entes sobrenaturales son asociados con este líquido. Ya vimos que se pensaba que estos podían robarse el alma de los niños que jugaban cerca de las aguas corrientes; sin embargo, esta no es la única tradición que existe en torno a este elemento y a sus entes asociados, porque existe otra narración de este pueblo de Tepec que nos ilustra sobre la naturaleza de estos seres del agua; esta la 


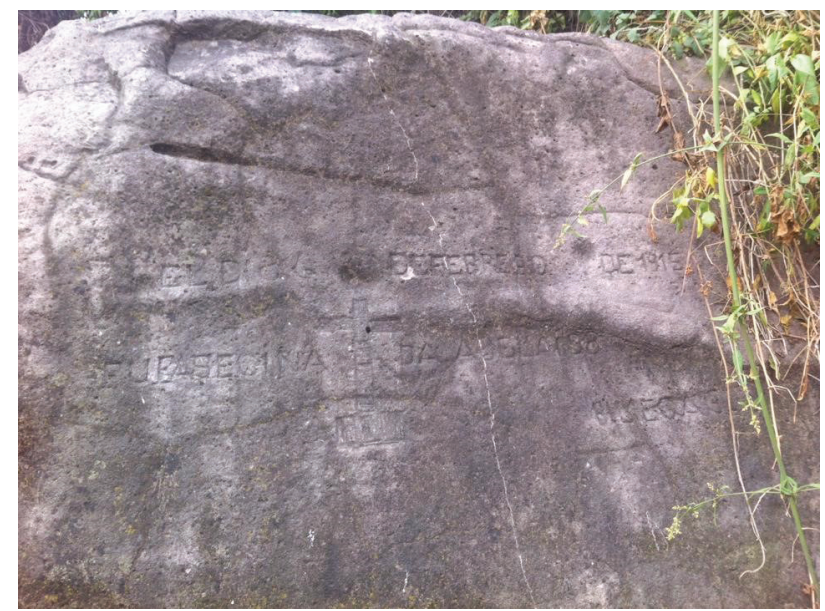

Figura 5: Epigrafía mortuoria en una enorme piedra en la localidad de Tepec. Esta roca alude al asesinato de una oriunda de la región en una pugna por el agua; esto ocurrió tras constantes peleas que habían tenido dos mujeres del pueblo por el agua de un pozo local. La inscripción dice: «El día 26 de febrero de 1915 fue asesinada Abelarda por el agua». Foto tomada el 29 de diciembre de 2017.

apreciamos en la del árbol del tecolote, nombre que le dan los pobladores a una enorme higuera que hunde sus raíces en el agua de un riachuelo y de la cual se cuentan muchas leyendas, ya que se dice que de dicho árbol salen diversos espíritus del agua como lo son los duendes y la Llorona, según lo que nos cuentan las narradoras:

[Silvia López Bañuelos:] Es un lugar, este, que yendo para, en el camino a, a, este, a Amacueca, por el camino a Amacueca, está por ahí una desviación y, este, hay una puerta así de reja, pero se puede entrar fácilmente... y, este, en el Tecolote pasa una corriente agua, y esa corriente de agua tiene una ceiba, no, no, no, una ceiba no, una..., ¡ay! ¿cómo se llama? Son árboles que son preferidos por la Llorona... ¿Cómo te he dicho que se llama? ¡Anita, Anita, ven! Oye, ahí en el Tecolote ¿cómo se llama el árbol que está ahí? [...] ¡Eso, es una higuera! ¡La higuera es preferida por la Llorona! Tienen que haber tres cosas: tiene que ser agua corriente, agua corriente y las raíces de la, de la higuera sumergidas en la corriente..., y no sé, pero les encanta ese lugar.

[Ana María Velazco Rodríguez:] Se supone que en la higuera hay una abertura donde ellos salen, porque ahí está el nacimiento de agua. Ahí está el nacimiento, y ellos, este, viven en el tronco, pero es uno enorme, un enorme tronco

[Silvia López Bañuelos:] ¿Los duendes?, pero ¿la Llorona?

[Ana María Velazco Rodríguez:] La Llorona también sale de ahí.

[Silvia López Bañuelos:] La Llorona también, espíritus, espíritus del agua, fíjate, espíritus que están allí, la Llorona. Porque a mí no me tocó en esa ocasión. Fuimos Anita y yo, y Alma, Alma iba con nosotros, porque a nosotros nos encantaba caminar por el cerro, bueno hasta nos fuimos hasta Canacatlán, de un pueblo a otro, caminamos como seis horas. Nos fuimos a media tarde y llegamos en la noche. Y, este..., me acuerdo yo que íbamos, llegamos ahí al Tecolote y estaba una roca, así como mesa, y nos llamó mucho la atención, pero nos asustaron porque íbamos dispuestas a ir al cerro, ahí por ese camino, pero nos dijeron: «Cuidado porque hay un animal de uña». Así les dicen a los pumas. No sé si era un puma o era una onza, y nos asustamos mejor y pusimos pies en polvorosa. Se me fue Anita, ¡Anita, sí, ven! A nosotras no nos tocó nada, ver nada, pero tú, a tu hermana Hilda que fueron de campo al Tecolote, ja ver, cuéntanos!

[Ana María Velazco:] Pues ellas dicen que estaban acomodando todo lo que llevaban de comida, sobre una roca, una roca que parece mesa, estaban todos arriba ahí, cuando de 
momento comenzaron a oír un viento fuerte y después del viento fuerte el grito horrible de la Llorona. No comieron, se dispersaron por todas partes.

[Silvia López Bañuelos:] Es un grito espantoso, tan terrible que, mira, te duelen las muelas, te revientan los oídos, sí, te enferma... Es terrible ese grito. Dicen que es la diosa no sé cuál, que llora por sus hijos, cuando la conquista de los españoles, que vinieron, y se dice que es esa diosa. ${ }^{3}$

En este ejemplo son detectables los siguientes motivos folclóricos, según se hallan catalogados en el Motif-Index de Thompson: Water Spirits (F420) y Magic Tree (D950); Espíritus del agua (F420) y Árbol mágico (D950). Aquí una vez más aparecen los duendes como entidades cercanas a las aguas; sin embargo, no se manifiesta evidente su función como ladrones de niños.

Según se aprecia, en esta tradición tepecana se hace una vinculación de los duendes con otro personaje sobrenatural muy popular en la narrativa de tradición oral mexicana: la Llorona; se dice además que ambos viven dentro de la higuera, una suerte de árbol maldito, de la que salen estos espíritus que molestan y aterran a la población. Una vinculación similar, en relatos de la Llorona y los duendes, se observa en las narraciones mostradas por Danira López Torres, donde se aprecia una doble función de estos seres en Chiapas, siendo en ocasiones buenos y en otras malos con los borrachos, en un tipo de relatos que son en su mayoría moralizantes (2017: 195-213).

En la última parte de este testimonio, se menciona que la Llorona es un personaje surgido de uno de los ocho Tetzahuitl, los presagios funestos de la conquista española, ya que, en el sexto de ellos, se menciona que en tiempos cercanos a la llegada de los conquistadores se escuchó llorar a la diosa Cihuacóatl, quien se lamentaba por la próxima destrucción de su progenie, el pueblo mexica (Magaloni Kerpel, 2016: 221-228).

El conocimiento y apropiación de esta tradición, de la caída de Tenochtitlan dentro de la literatura oral, no es exclusiva de este caso tepecano, ya que podemos encontrar varios ejemplos similares en otras narraciones populares como la siguiente recabada en Xochimilco:

La Llorona o Cihuacóatl es una diosa xochimilca, madre de los xochimilcas. Este, en la época prehispánica existieron varios dioses, incluyendo a la Cihuacóatl. A la llegada de los españoles ella predijo todo lo que iba a pasar, toda la destrucción que iban a tener, y ella empezó a llorar: «¡Ay, mis hijos!», que era en esa época de guerra y destrucción. Cuando llegaron los españoles, empezaron a tirar todos sus templos, sus dioses, que eran de piedra, y les impusieron la religión católica. Los españoles escucharon que había una mujer que lloraba entre los canales y las calles; al no poder pronunciar Cihuacóatl, pusieron la Llorona, de ahí el nombre. Es entonces por eso que le dicen que la Llorona, pero en realidad es la Cihuacóatl, la que dijo, la que gritaba «jay, mis hijos!», que eran en esa época de guerra y destrucción. Ana Teresa Cruz, ama de casa, Xochimilco, D. F., mayo, 2007. (Campos Moreno, 2008: 73)

La vinculación de la Llorona con los cuerpos de agua, al igual que en el caso de los duendes con los ríos, es común en diversas regiones de México, porque a esta se le

\footnotetext{
${ }^{3}$ Las narradoras fueron Silvia López Bañuelos y Ana María Velazco Rodríguez, ambas maestras de primaria, originarias de Tepec, Amacueca y residentes de Guadalajara, de 84 y 72 años respectivamente. Recogió: Víctor Manuel Bañuelos Aquino. Versión en línea de la grabación y la transcripción en la página web:

https://corpusdeliteraturaoral.ujaen.es/archivo/0872n-la-llorona-y-el-arbol-del-tecolote.
} 
suele describir como: «una mujer vestida de blanco que se encuentra especialmente por las orillas de los ríos, pantanos, lavaderos públicos» (Ortiz Guillén, 2016: 136), razón por la que en lugares como Xochimilco se cuentan diversas tradiciones sobre la Llorona en la que se le asocia con estos cuerpos de agua corriente:

vimos que venía bajando una señora y pensamos que era mi tía Toña, que nos andaba buscando. Y cuando iba pasando frente de nosotros sentimos que nos jalaban de los pelos y vimos que no pisaba el suelo, y pasó como a diez metros de donde estábamos nosotros. Como que volteó, y le vimos su cara como de caballo, y decía «jay, mis hijos!» Traía una canasta en el brazo y un rebozo cruzado Diez relatos de seres fantásticos en la tradición oral mexicana 73 en el cuerpo. La Llorona no nada más ese día se apareció: cada que llovía se oía gritar por las barrancas donde corre el agua. Silvestre Moreno Romero, chofer, mayo, 2007 (Campos Moreno, 2008: 72-73)

Llama la atención el nombre que la población le dio al árbol, del «tecolote», un ave que desde la antigüedad mesoamericana ha sido asociada al mundo de la muerte y lo sobrenatural, según los informantes de fray Bernardino de Sahagún, tradición que quedó registrada en su obra Historia general de las cosas de la Nueva España, escrita entre 1540-1585, en donde se explica que la aparición de esta ave nocturna similar a los búhos, y en específico su canto era un augurio de la muerte o la enfermedad: «También era tenido por augurio, se tenía por augurio, era conocido el agüero cuando el tecolote canta [...] Decían que cuando era oído, descubría la muerte, la enfermedad; era augurio de muerte» (López Austin, 1969: 34-35). ${ }^{4}$ Esto a su vez nos revela la persistencia de este imaginario precolombino en el poblado de Tepec y la naturaleza sobrenatural que se le atribuye a este árbol en el imaginario local: tanto la Llorona como el tecolote son vistos como entidades agoreras.

Recapitulando, este relato tepecano a la luz de otros similares de la República Mexicana nos ayuda a crear una visión más perfilada de los seres sobrenaturales que pueblan el imaginario de este lugar, así como sus diferencias y semejanzas con otros relatos con características similares. Aquí se reitera la representación de estos como espíritus del agua, dañinos para el ser humano, en especifico para aquellos que traspasan sus dominios. Una particularidad que vale la pena mencionar es la asociación de los espíritus del agua con la higuera, árbol que en esta tradición funge como su habitáculo, que por la manera en que hunde sus raíces en el agua y tiene un nombre que remite a una creencia ancestral sobre el mundo de la muerte, es una suerte de espacio liminal entre el mundo de los vivos y de las apariciones.

\section{CONCLUSIONES}

Se deducen de nuestros relatos las particularidades y características con las que se imagina y representa a los espíritus del agua, la Llorona y los duendes, en el poblado de Tepec. Encontramos que a pesar de la intensa religiosidad, medio católica, medio mágica, que impera en la población, y de la vinculación de los duendes con el demonio, y con las actividades de hostilidad y burla contra los humanos, tan presentes en los relatos de Artemio de Valle-Arizpe y los documentos de la Inquisición, no son apreciables en esta

\footnotetext{
${ }^{4}$ López Austin, en el libro Augurios y abusiones, incluye estas referencias de los informantes de fray Bernardino de Sahagún.
} 
tradición tepecana, ya que aunque estos son vistos como espíritus del agua vinculados con la muerte, no lo están ciertamente o de modo explícito con Satanás y los demonios.

A su vez, el acercamiento a los casos de campo nos mostró la asociación que se hace entre la Llorona y los duendes en Tepec, porque ambos son representados como espíritus del agua. Revisamos otros ejemplos mexicanos en que estos personajes del imaginario eran relacionados: a veces en relatos en los que se les aparecían a los borrachos; y en otros, como los de Xochimilco, en los que aparecen como entidades que transitan por los canales de esta zona a la vista de la población. En las narraciones tepecanas la cuestión medular y distintiva va a ser que tanto los duendes como la Llorona tienen como lugar de residencia el peculiar árbol del tecolote.

La asociación de los duendes con el agua, en el caso tepecano, probablemente tenga relación con el miedo de dejar a los niños cerca del agua, donde podían morir ahogados; estas fábulas enseñaban pues a los padres a ser más cuidadosos en la vigilancia de sus hijos cerca de este elemento, donde también se les recomendaba alejar a los duendes con cancioncillas como la ya referida, en un intento de mantener distanciadas a estas entidades de los niños, que como ya vimos en otra tradición, se pensaba que se llevaban a los infantes lejos de sus padres.

Todas estas entidades tienen como hábitat el agua, al menos en el imaginario, por la asociación que se suele hacer de este vital líquido con el mundo de los muertos, puesto que los cuerpos de agua como mares y ríos suelen ser vistos como fronteras simbólicas en la narrativa de tradición oral, que en algunas ocasiones separan y protegen, pero en otras neutralizan la capacidad de actuar (Pedrosa, 2015: 3-23). Por lo tanto, en estos relatos y tradiciones se evidencia la fascinación que este elemento ejerce sobre la población tepecana, que como pudimos advertir lo tienen presente en diversos medios, como epigrafia, literatura y su narrativa de tradición oral.

\section{BiBLIOGRAFÍA}

Ayala Calderón, Javier (2010): El Diablo en la Nueva España, México, Universidad de Guanajuato.

Ayala Calderón, Javier (2017): «El ente revisitado. Duendes y enduendamientos en la tradición oral y la literatura mexicana de los siglos XIX y XX», en $\mathrm{Del}$ inframundo al ámbito celestial. Entidades sobrenaturales de la literatura tradicional hispanoamericana, Carranza Vera, Claudia y Claudia Rocha Valverde (coordinadoras.)

BAÑUelos Aquino, «Representaciones y literatura oral acerca del demonio en los municipios de Amacueca y Tapalpa, en el sur de Jalisco», Boletín de literatura oral, 10 (2020), pp. 63-74. DOI: https://doi.org/10.17561/blo.v10.5235

Bierhorst, John (2003): Cuentos folklóricos latinoamericanos. Fábulas de las tradiciones hispanas e indígenas, Estados Unidos, Vintage español.

Campos Moreno, Araceli (2008): «Diez relatos de seres fantásticos en la tradición oral mexicana», Revista de literaturas populares, 1, pp. 67-74.

Carranza Vera, Claudia Carranza (2019): «De duendes enamorados. Tratamiento tradicional de un motivo en un caso recogido por el Santo Oficio novohispano», Edad de Oro, 38, pp. 203-229. DOI: https://doi.org/10.15366/edadoro2019.38.014

López Austin, Alfredo (1969): Augurios y abusiones, México, Universidad Nacional Autónoma de México. 
LÓPez Torres, Danira (2017): «Simbolismo ambivalente: la Llorona y el duende, apariciones en el camino del borracho», en Del inframundo al ámbito celestial. Entidades sobrenaturales de la literatura tradicional hispanoamericana, Carranza Vera, Claudia y Claudia Rocha Valverde (coordinadoras.)

Magaloni Kerpel, Diana (2016): Albores de la Conquista, México, Artes de México.

MARTínez Morales, José Luis (2006): «¿Literatura regional en tiempos de globalización?», en Investigación literaria y región, Betancourt, Ignacio (coordinador), México, COLSAN, pp. 11-27.

Merino, José María (2010): Leyendas españolas de todos los tiempos. Una memoria soñada, España, Siruela.

Ortiz Guillén, Adriana (2017): «“A mí me perdieron los duendes”: el encanto como transporte mágico», en Irás y no volverás. El viaje en formas narrativas de la literatura tradicional de México, Carranza Vera, Claudia, López Torres, Nora Danira y Mercedes Zavala Gómez del Campo (editoras), México, COLSAN.

OrTIZ Guillén, Adriana (2016): Personajes y espacios sobrenaturales en la tradición oral de Coatepec, Veracruz. URL: https://colsan.repositorioinstitucional.mx/jspui/ browse?type $=$ author $\&$ value $=$ ADRIANA + GUILLEN + ORTIZ .

Pedrosa, José Manuel (2015): «Odiseo, Gengi, el Cid y Gorba Dikko: soberbia épica, violencia verbal y frontera acuática», Atalaya, 15, pp. 1-28. DOI: 10.4000/ atalaya. 1564

Pérez CAStro, Ana Bella (2015): «Los chaneques siempre presentes en el sur de Veracruz», en Los habitantes del encanto. Seres extraordinarios en comunidades indigenas de América, Rocha, Claudia y Claudia Carranza, México, COLSAN, pp. 61-90.

Quezada Hernández, Marino (2008): Historia y leyendas de mi región, México, Secretaría de Cultura del Gobierno de Jalisco.

Rulfo, Juan (2005): El llano en llamas, México, Editorial RM.

Sandoval Godoy, Luis (1985): Testimonios, México, Unión editorial.

THOMPSON, Stith (1955-1958): Motif-index of folk-literature: a classification of narrative elements in folktales, ballads, myths, fables, mediaeval romances, exempla, fabliaux, jest-books, and local legends, Bloomington, Indiana University Press.

Valle-Arizpe, Artemio de (2008): Historia, tradiciones y leyendas de calles de México. Tomo 1, México, Lectorum.

Zavala Gómez del CAMPo, Mercedes (2013): «Hacia la delimitación de regiones folclóricas en México: la región centro-noreste del Altiplano», en Variación regional en la narrativa tradicional de México, González, Aurelio, Rodríguez Valle, Nieves y Zavala Gómez del Campo, Mercedes (eds.), México, COLSAN, pp. 29-44.

Fecha de recepción: 7 de enero de 2021

Fecha de aceptación: 22 de marzo de 2021

$$
\text { i }
$$

